\title{
Evaluating the rate of post-surgical complications between three surgical methods in management of pulmonary hydatid disease
}

\author{
Reza Bagheri ${ }^{1}$, Farideh Golhasani Keshtan ${ }^{2}$, Matin Moallem Shahri ${ }^{3}$, Bita Taghizadeh ${ }^{4}$, Reza Valian Dost ${ }^{1}$ \\ ${ }^{1}$ Lung Diseases Research Center, Mashhad University of Medical Sciences, Mashhad, Iran \\ ${ }^{2}$ Department of Physiology, Mashhad University of Medical Sciences, Mashhad, Iran \\ ${ }^{3}$ Department of Thoracic Surgery, Mashhad University of Medical Sciences, Mashhad, Iran \\ ${ }^{4}$ Department of Medical Biotechnology, School of Advanced Medical Sciences, Tabriz University of Medical Sciences, Tabriz, Iran
}

Kardiochir Torakochir Pol 2021; 18 (1): 23-26

\begin{abstract}
Introduction: Hydatid disease is a zoonotic disease caused by Echinococcus. Surgery remains the gold standard approach of treatment.

Aim: This study reports on 10 years of experience on surgical management of 78 cases of pulmonary hydatid disease and compares the rates of post-surgical complications between three approaches.

Material and methods: Three different surgical approaches - the Ugon method, cystectomy and lobectomy - were performed for pulmonary hydatid disease treatment during a 1-year follow-up program. The relationships between patient's age, sex, cyst location and surgical approach and occurrence of post-surgical complications were first assessed. Then post-surgical complications between these three methods were compared.

Results: From 78 patients, 51.5\% were female and 48.5\% were male (whose average age was 36.1). Hydatid cysts were found in the right (43.58\%) and left (37.17\%) lung while $19.23 \%$ of patients had bilateral cysts. Patient's age, sex and cyst location did not have any significant effect on the occurrence of complications. Post-surgical complications were only dependent on the surgical approach. $23 \%$ of the patients had post-surgical complications (including air leak, fistula, empyema, seroma and wound infection) and air leak was the most frequent one.

Conclusions: Since complications were only dependent on the surgical method, the rate of post-surgical complications were compared between the three approaches. Cystectomy and lobectomy had similar rates of complications, which were lower than that of the Ugon method. It can be concluded that cystectomy is the method of choice for management of pulmonary hydatid disease, with the lowest rate of complications.
\end{abstract}

Key words: hydatid cyst, pulmonary hydatid disease, cystectomy, post-operative hydatid cyst complications.

\section{Introduction}

Cystic hydatid disease is a common zoonosis caused by Echinococcus granulosus, which is the larval form of a canine tapeworm. Human infection occurs following ingestion of the eggs through contact with dogs or contaminated food or dirt. The eggs further transform into an oncosphere penetrating the intestinal wall and are carried by the bloodstream to different organs including the liver and lungs [1]. The liver and lungs are the most commonly infected organs. The clinical findings of hydatid cyst disease vary depending on the involved organs. Three layers of each hydatid cyst include: pericyst (outer layer), laminated membrane (middle layer) and germinal (inner layer) [2]. Hydatid cysts are generally asymptomatic and are accidental- ly diagnosed by clinical or radiological findings. Symptoms generally appear upon cyst rupture, bacterial infection or abdominal pain due to increased cyst size. Lung involvement may be present with dyspnea, fever, hemoptysis and cough. In the case of liver infection the symptoms may include hepatomegaly, presence of mass, obstructive jaundice, nausea and epigastric pain [3].

Hydatid disease management options include surgery, medication and percutaneous aspiration, injection and reaspiration (PAIR). However, surgery remains the preferred approach for treatment of pulmonary hydatid disease. The three main surgical procedures for pulmonary hydatid cyst eradication are cyst enucleation (the Ugon method), cystectomy and lobectomy.

Address for correspondence: Matin Moallem Shahri, Department of Thoracic Surgery, Mashhad University of Medical Sciences, Mashhad,

Iran, e-mail: Itrc@mums.ac.ir

Received: 13.07.2020, accepted: 25.10.2020. 


\section{Aim}

Our study reports on 10 years of surgical management of pulmonary hydatid disease patients with the aim of comparing these three surgical methods with respect to their outcome and complications.

\section{Material and methods}

This retrospective study was performed on 78 patients with pulmonary hydatid cyst in Qaem and Razavi Hospitals of Mashhad University of Medical Sciences, between 2009 and 2019. Studied variables include patient's age, sex, cyst location, surgical procedure and post-operative complications. Hydatid disease was diagnosed based on patient's history, physical examination, chest $\mathrm{X}$-ray and computed tomography (CT) scan. Ultrasound of the abdomen was also performed on patients with pulmonary hydatid disease in order to determine possible liver involvement. Patients with liver hydatid cysts were excluded from this study.

The experimental settings were described for the patients and written informed consent was obtained in advance. This research was approved by the Regional Ethics Committee of Mashhad University of Medical Sciences.

\section{Surgical procedure}

In this study, three surgical procedures were used for pulmonary cyst treatment, i.e. the Ugon method, cystectomy and lobectomy. Patients were divided into three groups as follows: A (cystectomy), B (the Ugon method) and C (lobectomy). In the Ugon method, after membrane removal, closure of bronchial openings and management of the residual cavity were performed by capitonnage or external drainage. Cystectomy involves whole cyst removal (including the pericyst) and subsequent cavity management. Lobectomy was performed when more than $60 \%$ of the lobe was involved or in the presence of unrepairable bronchial air opening. However, the surgical method was chosen depending

Table I. Patient groups based on cyst location and surgical procedure

\begin{tabular}{|c|c|c|c|c|}
\hline \multirow{2}{*}{$\begin{array}{l}\text { Cyst } \\
\text { location }\end{array}$} & \multicolumn{3}{|c|}{ Surgical procedure } & \multirow[t]{2}{*}{ Total } \\
\hline & $\begin{array}{c}\text { Group A } \\
\text { (Cystectomy) }\end{array}$ & $\begin{array}{c}\text { Group B } \\
\text { (Ugon method) }\end{array}$ & $\begin{array}{c}\text { Group C } \\
\text { (Lobectomy) }\end{array}$ & \\
\hline Right lung & 18 & 8 & 8 & 34 \\
\hline Left lung & 16 & 9 & 4 & 29 \\
\hline Bilateral & 5 & 9 & 1 & 15 \\
\hline Total & 39 & 26 & 13 & 78 \\
\hline
\end{tabular}

Table II. Post-operative complications of pulmonary hydatid disease in all patients $(n=78)$

\begin{tabular}{lc} 
Complications & Frequency \\
Wound infection & $2(2.56 \%)$ \\
\hline Air leak with residual space & $10(12.82 \%)$ \\
\hline Empyema & $2(2.56 \%)$ \\
\hline Seroma formation & $2(2.56 \%)$ \\
\hline Fistulas & $2(2.56 \%)$ \\
\hline
\end{tabular}

on the conditions throughout the surgery. Hypertonic saline solution $20 \%$ was used for residual cavity sterilization and prevention of contamination in adjacent tissues. All patients received albendazole $(10 \mathrm{mg} / \mathrm{kg} /$ day $)$ from 10 days prior to surgery until 6 months after surgery. The preferred surgical approach was determined based on cyst size, number and location (confirmed by CT scan), as well as clinical symptoms (infected and ruptured cyst) throughout surgery. Finally, the surgical outcome and post-operative complications were compared among these groups.

\section{Patient follow-up}

All patients received albendazole for 6 months after surgery in order to prevent hydatid disease recurrence [4]. Follow-up procedures consisted of chest X-ray, physical examination and liver function test (LFT). Chest X-ray was performed each month for the first 3 months after surgery and was repeated every 3 months until the end of the first post-operative year [5].

\section{Statistical analysis}

A logistic regression model was used to assess the contribution of patient's age, sex, cyst location and surgical method to occurrence of complications. Right-tailed exact Fisher's test was used to determine the probability of having postsurgical complications using MathWorks MATLAB R2020a. The $p$-value $\leq 0.05$ was considered statistically significant.

\section{Results}

Among 78 patients, pulmonary hydatid disease affected more females (51.5\%) than males (48.5\%). Patients' age range was $11-80$ with the average of 36.14 years old. In the context of cyst location, the lesions were detected in the right lung in 34 (43.58\%) cases, and in the left lung in 29 (37.17\%) cases. Bilateral cysts were present in 15 (19.23\%) cases. Types of surgical approach according to the cyst location are presented in Table I. Cystectomy and Ugon method were performed on patients with small cysts (less than $5 \mathrm{~cm}$ ), while larger and complicated (infected and ruptured) cysts were managed by lobectomy (Table I).

We then assessed the effects of patient's age, sex and cyst location, as well as the surgical method, on the probability of the occurrence of post-operative complication by fitting a logistic regression model to the data. We observed that only the surgical method had a significant effect on the probability of having post-surgical complications $\left(\beta_{\text {surgery }}\right.$ type $=0.95, p=0.0052 ; \beta_{\text {age }}=0.14, p=0.63 ; \beta_{\text {sex }}=-0.06$, $p=0.88 ; \beta_{\text {cyst location }}=-0.41, p=0.23$ ). The odds of having no post-surgical complications are higher for patients who underwent cystectomy compared to those who did not (righttailed Fisher's exact test, odds ratio 4.3750, $p=0.0132$ ).

From 78 patients, 18 (23\%) cases had post-surgical complications and no hospital mortality was observed. The most frequently observed post-operative complication was air leak (10 cases, 12.82\%). Other complications include wound infection, empyema and seroma and fistula formation, with an equal occurrence rate of $2.56 \%$ (Table II). 
The Ugon method had the highest rate of post-surgical complications among all methods. Of all the patients who underwent the Ugon approach, $46.15 \%$ had post-operative complications. This percentage was $10.25 \%$ for 39 patients who underwent cystectomy and $15.38 \%$ for 13 patients who underwent lobectomy (Figure 1).

In the Ugon method, 7 (26.92\%) patients had air leak, $2(7.69 \%)$ patients had seroma formation, while wound infection, empyema and fistula formation had equal occurrence (1 patient, 3.84\% for each complication). In the cystectomy group, 2 (5.12\%) patients had air leak, empyema and fistula formation had similar occurrence of $2.56 \%$ (1 patient for each complication), while no wound infection or seroma formation was observed. In the lobectomy group, no seroma, fistula or empyema formation was observed, only 1 (7.69\%) patient had air leak and 1 (7.69\%) patient had wound infection following surgery. As is evident from the results, air leak constitutes the majority of this high rate of complications in all of the groups (Table III).

\section{Discussion}

Surgery is the preferred approach for eradication of pulmonary hydatid cysts with the aim of preventing subsequent dissemination of the disease, while preserving healthy lung's parenchyma. In our study, we used three different surgical approaches for management of pulmonary hydatid cysts - the Ugon method, cystectomy and lobectomy - and compared the occurrence of the most common post-surgical complications between these techniques. The surgical approach depends on size, location and condition of the cysts (ruptured or infected). In this regard, it may be essential that the surgical procedures be personalized for each patient. However, the best surgical method is a conservative approach with minimal recurrence rate, complications and damage to the healthy surrounding tissues.

Some of the most commonly observed post-surgical complications following pulmonary hydatid cyst removal include prolonged air leak, wound infection, empyema, seroma and fistula formation $[6,7]$. We observed that air leak with residual space and wound infection had the highest frequency among complications in all the techniques used in our study.

First we assessed the impact of patient's age, sex and cyst location on the rate of post-surgical complications and observed that none of these parameters had a significant effect on the surgical outcome. Post-surgical complications was only affected by the surgical approach.

The Ugon method involves complete cyst removal through a parenchymal incision, in which the pericyst remains intact. This method is mainly suitable for small cysts and provides satisfactory results, since it leads to no subsequent lung tissue deformity. However, the main limitations of this method include high risk of air leak resulting in further bronchopleural fistula formation and infection of the remaining cavity [8]. According to our results, air leak was the main complication associated with this procedure.

The cystectomy approach relies on excision of the whole cyst (including the pericyst), while preserving the

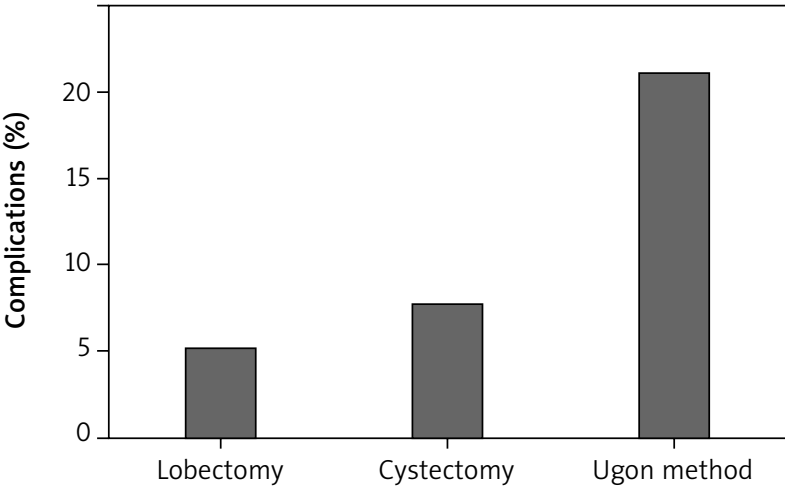

Figure 1. Post-operative complications among all patients in each surgical group $(n=78)$

Table III. Post-operative complications of all patients $(n=78)$ in three surgical groups

\begin{tabular}{lccc} 
Complication & $\begin{array}{c}\text { Ugon } \\
\text { method }\end{array}$ & Cystectomy & Lobectomy \\
Wound infection & 1 & 0 & 1 \\
\hline Empyema & 1 & 1 & 0 \\
\hline Seroma formation & 2 & 0 & 0 \\
\hline Fistula & 1 & 1 & 0 \\
\hline Air leak with residual space & 7 & 2 & 1 \\
\hline Total & 12 & 4 & 2 \\
\hline
\end{tabular}

healthy surrounding tissues is the priority and subsequent cavity management involves capitonnage. The main advantage of this technique is the low risk of recurrence due to pericyst removal along with the cyst. The risk of air leak is reduced, when capitonnage is performed for management of the residual cavity, which is also evident from our results showing a lower rate of air leak compared to the Ugon method. Pericyst removal may elevate the risk of tension pneumothorax and bronchopleural fistula formation and atelectasis due to lung tissue deformity [9-11]. However, in our study, fistula formation was less common in patients who underwent cystectomy compare to the Ugon method.

Lobectomy was first used in 1950 for large and complicated cysts and involves the removal of a lobe of the lung. The low rate of post-operative complications including bronchopleural fistula formation and infection due to complicated lesions is the main advantage of this technique. Lobectomy is considered a radical approach and lung tissue damage and lower stress compliance are the major complications associated with this technique [12]. In our results, no fistula formation was observed with lobectomy and only air leak and wound infection occurred.

The most frequent complications in our study were air leak, fistula and wound infection. In general, small cysts (less than $5 \mathrm{~cm}$ ) are managed by conservative approaches including the Ugon method or cystectomy. However, since, according to our results, cystectomy showed a lower rate of post-operative complications compared to the Ugon method, we suggest that this approach is more suitable for management of small cysts. 


\section{References}

1. McConnaughey M. Life Cycle of Parasites. In: Reference Module in Biomedical Sciences. Elsevier 2014.

2. Golzari SE, Sokouti M. Pericyst: the outermost layer of hydatid cyst. World J Gastroenterol 2014; 20: 1377-1378.

3. Firth J. Oxford Textbook of Medicine. 6th ed. Oxford University Press, New York 2018.

4. Tor M, Atasalihi A, Altuntas N, Sulu E, Senol T, Kir A, Baran R. Review of cases with cystic hydatid lung disease in a tertiary referral hospital located in an endemic region: a 10 years' experience. Respiration 2000; 67: 539-542.

5. Turk F, Yuncu G, Karabulut N, Türk T, Ozban M, Ali Zümrütbas E, Akdag B. A single-center large-volume experience in the surgical management of hydatid disease of the lung with and without extrapulmonary involvement. World J Surg 2013; 37: 2306-2312.
6. Shields TW. General Thoracic Surgery. Wolters Kluwer Health 2011.

7. Kaya SO, Liman ST, Bir LS, Yuncu G, Erbay HR, Unsal S. Horner's syndrome as a complication in thoracic surgical practice. Eur J Cardiothorac Surg 2003; 24: 1025-1028.

8. Ugon CV. Therapy of hydatid cysts of the lungs and their complications. J Int Chir 1952; 12: 155-178.

9. Perez Fontana V. Surgical treatment of pulmonary hydatid cyst by the Uruguayan method or pericystic extirpation. J Chir 1953; 69: 618-629.

10. Lichter I. Surgery of pulmonary hydatid cyst - the Barrett technique. Thorax 1972; 27: 529-534.

11. Ayas E. Hydatid cyst of the lung; surgical treatment according to Posadas' technic and according to modern methods. Prensa Med Argent 1952; 39: 2902-2914.

12. Susman M. Lobectomy for hydatid disease. Med J Aust 1951; 1: 400-403. 